OPEN ACCESS

Edited by:

Juel Jarani,

Sports University of Tirana, Albania

Reviewed by:

Yang Zhang,

Independent Researcher, Orlando, FL,

United States

Xin Xue,

Hangzhou Normal University, China Bobana Berjan Bacvarevic,

University of Belgrade, Serbia

*Correspondence:

$\mathrm{Te} B \mathrm{Bu}$

616387696@qq.com

Specialty section

This article was submitted to

Children and Health,

a section of the journal

Frontiers in Pediatrics

Received: 23 February 2021

Accepted: 29 March 2021

Published: 27 April 2021

Citation:

Bu T, Popovic S, Huang H, Fu T and

Gardasevic J (2021) Relationship

Between National Economic

Development and Body Mass Index in

Chinese Children and Adolescents

Aged 5-19 From 1986 to 2019

Front. Pediatr. 9:671504.

doi: 10.3389/fped.2021.671504

\section{Relationship Between National Economic Development and Body Mass Index in Chinese Children and Adolescents Aged 5-19 From 1986 to 2019}

\author{
$\mathrm{Te} \mathrm{Bu}^{1 *}$, Stevo Popovic ${ }^{2,3}$, Huiqing Huang ${ }^{1}$, Tao $\mathrm{Fu}^{4}$ and Jovan Gardasevic ${ }^{2,3}$ \\ ${ }^{1}$ Faculty of Sport and Physical Education, Hunan Normal University, Changsha, China, ${ }^{2}$ Faculty for Sport and Physical \\ Education, University of Montenegro, Niksic, Montenegro, ${ }^{3}$ Montenegrin Sports Academy, Podgorica, Montenegro, ${ }^{4}$ Faculty \\ of Health and Exercise Science, Tianjin University of Sport, Tianjin, China
}

Obesity represents a major risk factor for population health. No studies have evaluated how economic expansion impacts the prevalence of obesity. The purpose of this study was to assess the relationship between national economic development and body mass index (BMI) in Chinese children and adolescents. Data of mean BMI in children and adolescents aged 5-19 from 1986 to 2019 were extracted from an international database of cardiometabolic risk factors. Chinese economic development was quantified by the gross domestic product (GDP), which was extracted from the International Monetary Fund. The relationships between GDP and BMI were assessed in 1-year age groups for ages 5-19 years. In addition, the linear regression from the main data and estimated GDP growth allowed the projections of mean BMl for each age group between 2020 and 2025. The results suggest there was a linear increase in BMl over years, which means that there has been a steady increase in BMl over the economic expansion. Overall, 97\% of the variance (Pearson correlation coefficient) of BMI in boys can be explained by the GDP expansion, and the same pattern (98\% of the variance) occurred in girls. Projected mean BMI were provided for constructing future national strategies to prevent overweight and obesity in youth. In conclusion, BMI in children and adolescents aged 5-19 trended upwards between 1986 and 2019. Our analyses for the first time suggest that globalization has a major impact on BMI in China. Economic expansion was highly predictive of BMl increases.

Keywords: obesity, overweight, gross domestic product, economic growth, supply-side economy

\section{INTRODUCTION}

Obesity has emerged a global health problem and posed health risks to the world's population of all ages. According to the World Health Organization, the worldwide prevalence of obesity has tripled between 1975 and 2020 (1). In 2016, more than 1.9 billion adults aged 18 years and over were overweight, whereas over 340 million children and adolescents aged 5-19 were overweight or obese (1). More recently, data have shown that 38 million children worldwide under the age of 5 were overweight or obese in 2019 (1). The prevalence of overweight and obesity in childhood is 
high and continues to increase globally (2-5), generating an increasing health risk. The same trend is occurring in China, which is facing this major public health concern. Between 1995 and 2014, Chinese children and adolescents aged 7-18 saw a four-fold increase in overweight and obesity, with around 1 in 5 children and adolescents being either overweight or obese (6). Population data show that prevalence of overweight continually increased from $1.1 \%$ in 1985 to $20.4 \%$ in 2014 in Chinese schoolaged children (7), making childhood obesity a critical health issue in China.

The etiology of obesity is complex. Although the genetic susceptibility to obesity is high (8), the rising global prevalence of obesity highlights behavioral changes associated with modern lifestyles (e.g., excessive intake of simple carbohydrates and sugar, physical inactivity) that contribute to its development $(9,10)$. A vital effect that has not yet been reported in the literature is the role of economic expansion in the development of overweight and obesity. For example, it has been suggested that rising obesity can be attributed to factors related to globalization processes, which can be related to flooding developing economies with western-style, inexpensive but obesogenic fast foods (11).

However, current literature shows conflicting results about the relationship between economic development and obesity. Rapid emergences of overweight and obesity are widely documented, even in the poorest countries of sub-Saharan Africa (12), which exhibit little economic expansion in the past decade. In general, Seydel et al. (13) suggested that economic growth leads to increase of overweight and obesity in developing countries. Specifically, $1 \%$ increase in income leads to around a 0.2 and $0.3 \%$ increase in the overweight and obesity prevalence, respectively (14). For instance, compared with adult women living in poorest households in Nepal, the odds of being overweight were, respectively $3.44,2.12,1.46$, and 1.19 times higher for women living in richest, richer, middle and poorer wealth status households (15). As a result, accompanying with rapid economic growth, emerging economies are undergoing a noticeable shift in the disease structure marked by increasingly higher proportion of non-communicable disease-related morbidities $(6,16)$. However, among developed economies, higher gross domestic product (GDP) predicted lower body mass index (BMI) (11).

Coincident with economic development, China has experienced a marked transition from undernutrition to overweight and obesity since the reform and opening up of Chinese economy $(6,7)$. An important step in addressing the growing overweight and obesity trend in China, as well as in the global community where obesity has literally become an epidemic, is understanding all key factors, including national economic development, associated with childhood and adolescent obesity. Given the critical impact that childhood and adolescent obesity has on lifetime health (17), it is crucial to explore the relationship between rapid expansion of the Chinese economy and BMI, the most commonly used measure for assessing obesity. Therefore, the purpose of this study was to evaluate the relationship between an economic factor (GDP) and BMI in children and adolescents aged 519 in China. In addition, we projected the trend change in BMI between 2020 and 2025, which should offer national policy makers to design more targeted strategies to combat youth overweight and obesity. This study is first of its kind in China.

\section{METHODS}

\section{Data Sources}

BMI data were available from an international database on cardiometabolic risk factors managed by the NonCommunicable Disease Risk Factor Collaboration (18). This database is continuously updated and national data (i.e., mean BMI of China Mainland) used in this study were extracted as of 31 December 2020. While the total sample sizes for country specific data are not available, BMI data collected by the Non-Communicable Disease Risk Factor Collaboration currently consist of 2,181 population-based studies with 65 million participants, which is considered to be the most comprehensive international scientific endeavor documenting trend change in BMI. GDP data of China Mainland between 1986 and 2019 were available from the International Monetary Fund (19).

\section{Statistical Analysis}

Since linear function yielded same results as the first order polynomial function, we used linear regression to explore the relationship between GDP and BMI. Pearson correlation coefficients were used to quantify associations between GDP and BMI. Linear regression for each age group allowed us to project the trend development of BMI. We used a real GDP annul growth of $2.3 \%$ for 2020 (19), and projected real GDP annul growth of $6.0 \%$ between 2021 and 2025 (20) to calculate the GDP growth and subsequently projected change in BMI from 2020 to 2025. Prism 9 (GraphPad Software, San Diego) was used to conduct the analyses in this study.

\section{RESULTS}

Scatter plots with respective correlation coefficients and linear regression lines are depicted in Figures 1, 2. There has been a steady increase in BMI over the measured 35 years. Linear regression revealed that GDP expansion was associated with increased BMI in children and adolescents over the time. In general, this pattern was seen in both boys $\left(R^{2}=97 \%\right)$ and girls $\left(R^{2}=98 \%\right)$.

Using the economic growth model, projected BMI in 20202025 is shown in Table 1. Overall, it is projected that economic expansion over the next 6 years could yield around 0.80 and $0.51 \%$ annual increase in BMI occurrence for boys and girls aged $5-19$, respectively.

\section{DISCUSSION}

This is the first study of the relationship between national economic development and BMI in China. Results from this study show for the first time that higher BMI in both boys and girls and in all age groups between 5 and 19 was strongly related to the economic expansion in the past 35 years in China. From 

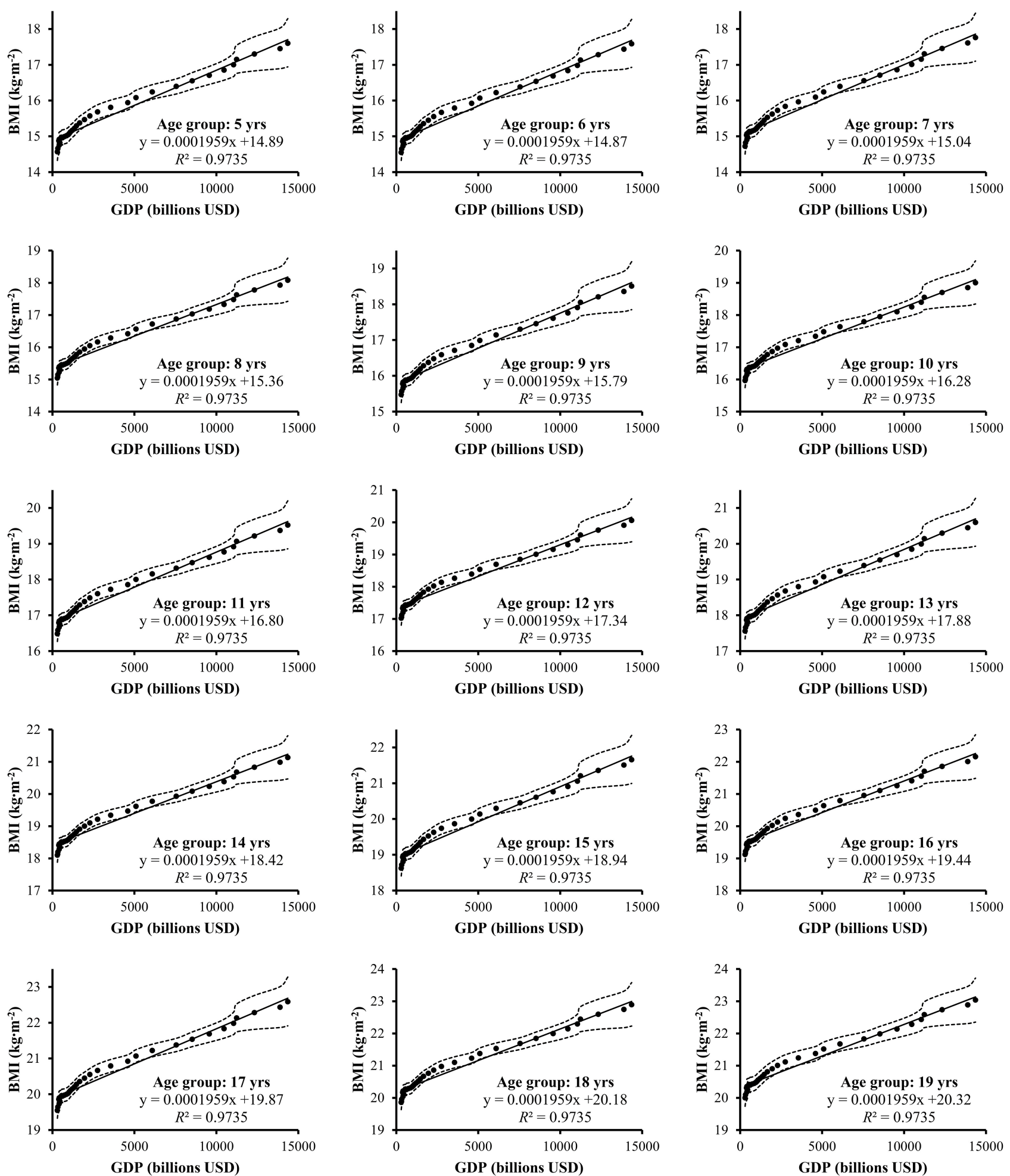

FIGURE 1 | Scatter plots with linear regression lines of gross domestic product (GDP) and body mass index (BMI) of Chinese boys aged 5-19 with respective Pearson correlation coefficients. Dotted lines represent 95\% confidence interval.

the epidemiological point of view, the increase in BMI was related to the rapid and strong economic growth in China, which should constitute an important public health concern in modern China.
The current study aligns with substantial evidence that overweight and obesity among Chinese school-aged children and adolescents are trending upwards since the twenty-first 

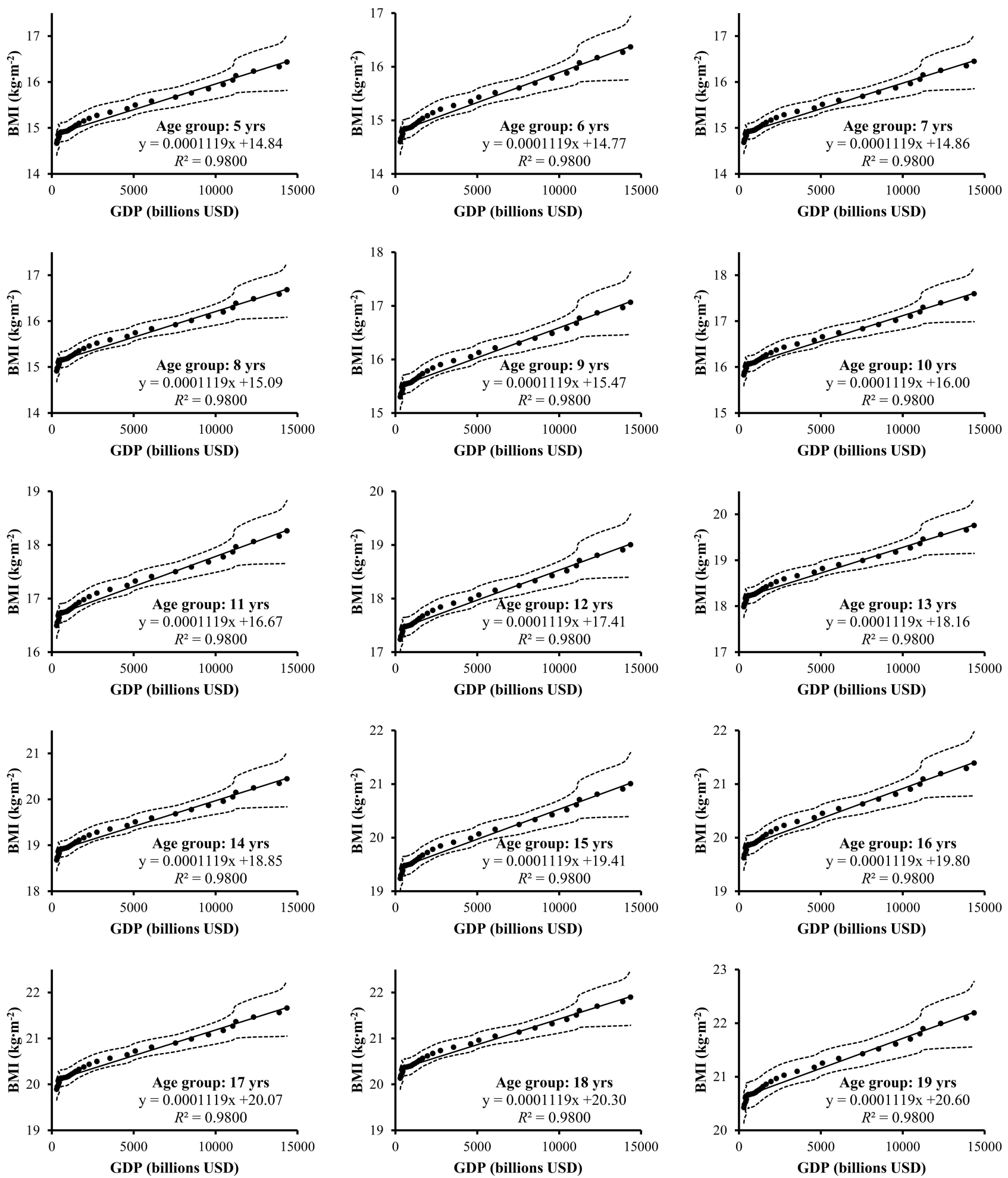

FIGURE 2 | Scatter plots with linear regression lines of gross domestic product (GDP) and body mass index (BMI) of Chinese girls aged 5-19 with respective Pearson correlation coefficients. Dotted lines represent $95 \%$ confidence interval.

century. For instance, Zhang et al. (21) found that between 2010 and 2015, the age-adjusted prevalence of overweight and obesity among boys increased from 21.2 to $31.7 \%$ and from 10.6 to $16.9 \%$ among girls. As the evidence accrues, this study first provides a readily available macro-indicator for explaining temporal trends of overweight and obesity in 
TABLE 1 | Projected mean body mass index of Chinese children and adolescents aged 5-19 between 2020 and 2025.

\begin{tabular}{|c|c|c|c|c|c|c|c|c|c|c|c|c|}
\hline \multirow[t]{2}{*}{ Age group (years) } & \multicolumn{2}{|c|}{$\begin{array}{l}2020 \text { BMI } \\
\left(\mathrm{kg} \cdot \mathrm{m}^{-2}\right)\end{array}$} & \multicolumn{2}{|c|}{$\begin{array}{l}2021 \text { BMI } \\
\left(\mathbf{k g} \cdot \mathrm{m}^{-2}\right)\end{array}$} & \multicolumn{2}{|c|}{$\begin{array}{l}2022 \text { BMI } \\
\left(\mathbf{k g} \cdot \mathrm{m}^{-2}\right)\end{array}$} & \multicolumn{2}{|c|}{$\begin{array}{l}2023 \text { BMI } \\
\left(\mathrm{kg} \cdot \mathrm{m}^{-2}\right)\end{array}$} & \multicolumn{2}{|c|}{$\begin{array}{c}2024 \text { BMI } \\
\left(\mathbf{k g} \cdot \mathrm{m}^{-2}\right)\end{array}$} & \multicolumn{2}{|c|}{$\begin{array}{c}2025 \text { BMI } \\
\left(\mathrm{kg} \cdot \mathrm{m}^{-2}\right)\end{array}$} \\
\hline & Boys & Girls & Boys & Girls & Boys & Girls & Boys & Girls & Boys & Girls & Boys & Girls \\
\hline 5 & 17.8 & 16.5 & 17.9 & 16.6 & 18.1 & 16.7 & 18.3 & 16.8 & 18.5 & 16.9 & 18.7 & 17.0 \\
\hline 6 & 17.7 & 16.4 & 17.9 & 16.5 & 18.1 & 16.6 & 18.3 & 16.7 & 18.5 & 16.8 & 18.7 & 17.0 \\
\hline 7 & 17.9 & 16.5 & 18.1 & 16.6 & 18.3 & 16.7 & 18.5 & 16.8 & 18.7 & 16.9 & 18.9 & 17.1 \\
\hline 8 & 18.2 & 16.7 & 18.4 & 16.8 & 18.6 & 16.9 & 18.8 & 17.0 & 19.0 & 17.2 & 19.2 & 17.3 \\
\hline 9 & 18.7 & 17.1 & 18.8 & 17.2 & 19.0 & 17.3 & 19.2 & 17.4 & 19.4 & 17.5 & 19.6 & 17.7 \\
\hline 10 & 19.2 & 17.6 & 19.3 & 17.7 & 19.5 & 17.8 & 19.7 & 18.0 & 19.9 & 18.1 & 20.1 & 18.2 \\
\hline 11 & 19.7 & 18.3 & 19.9 & 18.4 & 20.0 & 18.5 & 20.2 & 18.6 & 20.4 & 18.7 & 20.7 & 18.9 \\
\hline 12 & 20.2 & 19.1 & 20.4 & 19.2 & 20.6 & 19.3 & 20.8 & 19.4 & 21.0 & 19.5 & 21.2 & 19.6 \\
\hline 13 & 20.8 & 19.8 & 20.9 & 19.9 & 21.1 & 20.0 & 21.3 & 20.1 & 21.5 & 20.2 & 21.7 & 20.4 \\
\hline 14 & 21.3 & 20.5 & 21.5 & 20.6 & 21.7 & 20.7 & 21.8 & 20.8 & 22.1 & 20.9 & 22.3 & 21.0 \\
\hline 15 & 21.8 & 21.1 & 22.0 & 21.2 & 22.2 & 21.3 & 22.4 & 21.4 & 22.6 & 21.5 & 22.8 & 21.6 \\
\hline 16 & 22.3 & 21.4 & 22.5 & 21.5 & 22.7 & 21.6 & 22.9 & 21.8 & 23.1 & 21.9 & 23.3 & 22.0 \\
\hline 17 & 22.7 & 21.7 & 22.9 & 21.8 & 23.1 & 21.9 & 23.3 & 22.0 & 23.5 & 22.1 & 23.7 & 22.3 \\
\hline 18 & 23.1 & 21.9 & 23.2 & 22.0 & 23.4 & 22.1 & 23.6 & 22.3 & 23.8 & 22.4 & 24.0 & 22.5 \\
\hline 19 & 23.2 & 22.2 & 23.4 & 22.3 & 23.6 & 22.4 & 23.7 & 22.6 & 24.0 & 22.7 & 24.2 & 22.8 \\
\hline
\end{tabular}

BMI, body mass index.

China. Very importantly, this study allows a projection of BMI. We estimate by 2025 , BMI will increase to $21.1 \mathrm{~kg} \cdot \mathrm{m}^{-2}$ for boys and $19.6 \mathrm{~kg} \cdot \mathrm{m}^{-2}$ for girls in China. This can allow public health administrators to construct more targeted policy interventions for the prevention of overweight and obesity among youth. Specifically, relevant governing bodies in China can establish expert panels consisting of policy makers and health professionals and researchers, to construct national strategies on combating negative consequences related to the trending childhood overweight and obesity in China. Should this upwards trend of BMI among the young population be controlled, not only it could be translated to reduced health burdens for the society as a whole, but it could also further boost the Chinese economy in the long run as suggested in an economic model by Kelly et al. (22). Hence, the current results could be very important.

Although the overall BMI is still in the normal range, the physiological impact of overweight and obesity is greater among Chinese population compared to westerners. At the same BMI, risks for the development of metabolic and cardiovascular diseases are elevated for Chinese ethnicities compared to westerners $(23,24)$. The risk for developing hypertension is doubled in Chinese with BMI between 23.0 and $24.9 \mathrm{~kg} \cdot \mathrm{m}^{-2}$ and tripled with BMI between 25.0 and $26.9 \mathrm{~kg} \cdot \mathrm{m}^{-2}$ (25). Therefore, BMI cut points for overweight and obesity in Asians were lowered to $23.0-27.4 \mathrm{~kg} \cdot \mathrm{m}^{-2}$ and $\geq 27.5 \mathrm{~kg} \cdot \mathrm{m}^{-2}$, respectively, compared to standard BMI cut points for overweight $\left(25.0-29.9 \mathrm{~kg} \cdot \mathrm{m}^{-2}\right)$ and obese $\left(\geq 30.0 \mathrm{~kg} \cdot \mathrm{m}^{-2}\right)$ in western nations (26).

Based on the trend analyses, BMI among the young Chinese population continues to increase, and this trend may be more important than ever for health providers and national policy makers. It is expected that the Chinese economy will continue to expand at $6 \%$ annual rate (20), and according to this study's regression model, this economic growth rate will be translated to 0.80 and $0.51 \%$ annual increase in BMI for Chinese boys and girls, respectively. Thus, healthy weight management and obesity prevention protocols should be included in the national education system and those establishing the BMI cut-off point used to identify obesity need to carefully consider the Chinese specific difference in relation to the cardiovascular risk spanning through childhood and adulthood.

It should be notated that a correlation does not allow for causal inference but can provide a framework to guide future investigations and interventions. In our study, the Chinese GDP expansion was highly predictive of BMI increase in Chinese children and adolescents, which is in line with findings from other developing economies $(15,16)$. However, overweight and obesity are also growing in countries where GDP are not growing continuously (12). Furthermore, as countries develop economically, overweight prevalence remains mostly unchanged among the wealthiest countries (27). This should not be surprising though. Increase in population BMI is driven by many factors, including the human development index (HDI) (14). HDI is a summary measure of average achievement in key dimensions of human development, including a long and healthy life, being knowledgeable and have a decent standard of living (28). Although rising income per capita tends to push populations toward unhealthy western eating habits, in the very high HDI countries, there is a positive effect on eating habits of any further improvement in per capita income (14). China have witnessed a marked transition in its diet, activity and nutritional status patterns during the rapid economic expansion. According to the latest "Report on Nutrition and Chronic Disease Status of Chinese Residents (2020)" (29), the Chinese dietary pattern has shifted toward a dietary pattern with high consumption 
of meats and edible oil but low consumption of cereals and vegetables. Children and teenagers' frequent drinking of sugary beverages and insufficient physical activity are widespread. The net effect of all these changes in diet has been to increase in total energy intake and consequently higher prevalence in overweight and obesity among Chinese residents. Taken collectively, there is a pressing need for national policy adjustments to extend beyond an emphasis on rapid economic growth alone, and to campaign on healthy diets and lifestyles to achieve synchronized improvement in HDI.

As has been mentioned in the methods, the present study has an inherent limitation from data source. The study used BMI data from an international database where neither the sample sizes nor the quality of these data collection can be verified independently. It is possible that not all studies were of similar quality in terms of randomization and convenience sampling. Thus, the impact of these limiting factors on the current analysis is unclear. However, the Non-Communicable Disease Risk Factor Collaboration is internationally recognized databases that collect data from peerreviewed literatures. Nonetheless, we acknowledge the present conclusion may change as future studies appear in the literature and merit future continuous investigation.

Although the causation for the relationship between GDP and BMI is beyond the scope of this study, our data provide the first insight on how globalization impacts BMI. An important implication is that resolving this health epidemic should not only rely on traditional health-based guidelines. The present results could help launch a comprehensive national obesity initiative, while laying the foundations for physical well-being into 2021-2025. Future task forces for designing pediatric practice should also attempt to explore the influence of targeted economic activities.

From the macro-perspective, the present results could offer novel insights to reverse-engineer a positive economic impact that stimulates not only supply-side economy but also demandside related social changes. We recommend health professionals and economists jointly assess how reduced reliance on ultraprocessed foods related to globalization could yield positive economic and health outcomes. For instance, the recent booming of fresh food e-commerce in China, a market valued at

\section{REFERENCES}

1. World Health Organization. Obesity and Overweight. (2020). Available online at: https://www.who.int/news-room/fact-sheets/detail/obesity-andoverweight (accessed December 31, 2020).

2. Spinelli A, Buoncristiano M, Kovacs VA, Yngve A, Spiroski I, Obreja G, et al. Prevalence of severe obesity among primary school children in 21 European countries. Obesity Facts. (2019) 12:244-58. doi: 10.1159/000500436

3. Ogden CL, Carroll MD, Lawman HG, Fryar CD, Kruszon-Moran D, Kit $\mathrm{BK}$, et al. Trends in obesity prevalence among children and adolescents in the United States, 1988-1994 through 2013-2014. JAMA. (2016) 315:2292-9. doi: 10.1001/jama.2016.6361

4. Mazidi M, Banach M, Kengne AP, Lipid, Blood Pressure Meta-analysis Collaboration Group. Prevalence of childhood and adolescent overweight and obesity in Asian countries: a systematic review and meta-analysis. Arch Med Sci. (2018) 14:1185. doi: 10.5114/aoms.2018.79001
200 billion Chinese Yuan in 2020 (30), may provide an excellent opportunity to better control the curve of population weight gain, should consumer behaviors be driven to the consumption of healthy fresh foods. Together with traditional promotion of active lifestyles (e.g., daily walking for 8,000 steps per day), comprehensive nationwide interventions containing novel economic approaches could creatively reduce overweight and obesity whilst stimulating the high-quality, health-related consumer economy in China.

\section{CONCLUSION}

China was, and still is, one of the fastest growing economies in the world. With obesity on the rise across the nation, plus an increased risk at lower BMI cut points among Chinese ethnicities for chronic diseases, it is important to acknowledge and understand how rapid economic expansion affected this process. This study's findings on the strong linear relationship between national economic development and BMI highlight the need for alternative economic interventions and strategies tailored for the young Chinese population to control overweight and obesity through adulthood. We expect that a carefully planned, innovative approach could simultaneously help change consumer behaviors and yield enhanced health outcomes and economic growth in modern China.

\section{DATA AVAILABILITY STATEMENT}

The raw data supporting the conclusions of this article will be made available by the authors, without undue reservation.

\section{AUTHOR CONTRIBUTIONS}

TB and SP contributed conception and design of the study. $\mathrm{HH}$ and TF helped design and coordinate data collection. TB, $\mathrm{HH}$, and TF performed the statistical analyses and wrote the first draft of the manuscript. SP and JG critically reviewed and edited the manuscript. All authors contributed to manuscript revision, read, and approved the submitted version.
5. Sartorius B, Sartorius K, Taylor M, Aagaard-Hansen J, Dukhi N, Day C, et al. Rapidly increasing body mass index among children, adolescents and young adults in a transitioning population, South Africa, 2008-15. Int J Epidemiol. (2017) 47:942-52. doi: 10.1093/ije/dyx263

6. Dong Y, Jan C, Ma Y, Dong B, Zou Z, Yang Y, et al. Economic development and the nutritional status of Chinese school-aged children and adolescents from 1995 to 2014: an analysis of five successive national surveys. Lancet Diabetes Endocrinol. (2019) 7:288-99. doi: 10.1016/S2213-8587(19)30075-0

7. Song Y, Agardh A, Ma J, Li L, Lei Y, Stafford RS, et al. National trends in stunting, thinness and overweight among Chinese school-aged children, 1985-2014. Int J Obesity. (2019) 43:402-11. doi: 10.1038/s41366-018-0129-7

8. Rohde K, Keller M, la Cour Poulsen L, Blüher M, Kovacs P, Böttcher Y. Genetics and epigenetics in obesity. Metabolism. (2019) 92:37-50. doi: 10.1016/j.metabol.2018.10.007

9. Liu L, Wang M, Li Y, Liu H, Hou C, Zeng Q, et al. Low-tomoderate fluoride exposure in relation to overweight and obesity among 
school-age children in China. Ecotoxicol Environ Safety. (2019) 183:109558. doi: 10.1016/j.ecoenv.2019.109558

10. Zhu Z, Tang Y, Zhuang J, Liu Y, Wu X, Cai Y, et al. Physical activity, screen viewing time, and overweight/obesity among Chinese children and adolescents: an update from the 2017 physical activity and fitness in China-the youth study. BMC Public Health. (2019) 19:1-8. doi: 10.1186/s12889-019-6515-9

11. Fox A, Feng W, Asal V. What is driving global obesity trends? Globalization or "modernization"? Global Health. (2019) 15:1-16. doi: 10.1186/s12992-019-0457-y

12. Popkin BM, Adair LS, Ng SW. Global nutrition transition and the pandemic of obesity in developing countries. Nutr Rev. (2012) 70:3-21. doi: 10.1111/j.1753-4887.2011.00456.x

13. Seydel GS, Kucukoglu O, Altinbas A, Demir OO, Yilmaz S, Akkiz H, et al. Economic growth leads to increase of obesity and associated hepatocellular carcinoma in developing countries. Ann Hepatol. (2017) 15:662-72. doi: 10.5604/16652681.1212316

14. Ferretti F, Mariani M. Simple vs. complex carbohydrate dietary patterns and the global overweight and obesity pandemic. Int J Environ Res Public Health. (2017) 14:1174. doi: 10.3390/ijerph14101174

15. Bishwajit G. Household wealth status and overweight and obesity among adult women in Bangladesh and Nepal. Obesity Sci Pract. (2017) 3:185-92. doi: $10.1002 / 0 s p 4.103$

16. Luhar S, Mallinson PAC, Clarke L, Kinra S. Trends in the socioeconomic patterning of overweight/obesity in India: a repeated cross-sectional study using nationally representative data. BMJ Open. (2018) 8:e023935. doi: 10.1136/bmjopen-2018-023935

17. McPhee PG, Singh S, Morrison KM. Childhood obesity and cardiovascular disease risk: working towards solutions. Can J Cardiol. (2020) 36:1352-61. doi: 10.1016/j.cjca.2020.06.020

18. NCD Risk Factor Collaboration. (2020). Available online at: https://ncdrisc. org/ (accessed December 31, 2020).

19. International Montetary Fund. People's Republic of China and the IMF. (2020). Available online at: https://www.imf.org/en/Countries/CHN (accessed March 21, 2021).

20. Qiu S, Yao K. China Sets 'Low Bar' for GDP Growth, Pledges More Jobs. (2021). Available online at: https://www.reuters.com/article/us-chinaparliament-gdp/china-sets-low-bar-for-gdp-growth-pledges-more-jobsidUSKBN2AX03L (accessed March 21, 2021).

21. Zhang J, Li X, Hawley N, Zheng Z, Zou Z, Tan L, et al. Trends in the prevalence of overweight and obesity among Chinese school-age children and adolescents from 2010 to 2015. Child Obesity. (2018) 14:182-8. doi: 10.1089/chi.2017.0309
22. Kelly IR, Doytch N, Dave D. How does body mass index affect economic growth? A comparative analysis of countries by levels of economic development. Econ Hum Biol. (2019) 34:58-73. doi: 10.1016/j.ehb.2019.03.004

23. Chooi YC, Ding C, Magkos F. The epidemiology of obesity. Metabolism. (2019) 92:6-10. doi: 10.1016/j.metabol.2018.09.005

24. Deurenberg-Yap M, Chew S, Deurenberg P. Elevated body fat percentage and cardiovascular risks at low body mass index levels among Singaporean Chinese, Malays and Indians. Obesity Rev. (2002) 3:209-15. doi: 10.1046/j.1467-789X.2002.00069.x

25. Cheung GW, Lau RS. Testing mediation and suppression effects of latent variables: Bootstrapping with structural equation models. Organ Res Meth. (2008) 11:296-325. doi: 10.1177/1094428107300343

26. Consultation WE. Appropriate body-mass index for Asian populations and its implications for policy and intervention strategies. Lancet. (2004) 363:157-63. doi: 10.1016/S0140-6736(03)15268-3

27. Templin T, Cravo Oliveira Hashiguchi T, Thomson B, Dieleman J, Bendavid E. The overweight and obesity transition from the wealthy to the poor in low-and middle-income countries: a survey of household data from 103 countries. PLoS Med. (2019) 16:e1002968. doi: 10.1371/journal.pmed.10 02968

28. United Nations Development Programme. Human Development Reports. (2020). Available online at: http://hdr.undp.org/en/content/latest-humandevelopment-index-ranking (accessed March 21, 2021).

29. National Health Commission. Report on Nutrition and Chronic Disease Status of Chinese Residents (2020). (2021). Available online at: http://www.scio. gov.cn/xwfbh/xwbfbh/wqfbh/42311/44583/wz44585/Document/1695276/ 1695276.htm (accessed March 21, 2021).

30. Sina Finance. Booming of Fresh Food E-Commerce in China. (2020). Available online at: https://finance.sina.com.cn/chanjing/cyxw/2020-04-20/ doc-iirczymi7283036.shtml (accessed December 31, 2020).

Conflict of Interest: The authors declare that the research was conducted in the absence of any commercial or financial relationships that could be construed as a potential conflict of interest.

Copyright (c) 2021 Bu, Popovic, Huang, Fu and Gardasevic. This is an open-access article distributed under the terms of the Creative Commons Attribution License (CC $B Y)$. The use, distribution or reproduction in other forums is permitted, provided the original author(s) and the copyright owner(s) are credited and that the original publication in this journal is cited, in accordance with accepted academic practice. No use, distribution or reproduction is permitted which does not comply with these terms. 